\title{
Experimental Study on Assemble-type Composited Wall
}

\author{
Yuanyuan Zhao ${ }^{1,}$, Quan Yuan ${ }^{1, b}$ \\ ${ }^{1}$ Beijing Jiaotong University, Beijing China

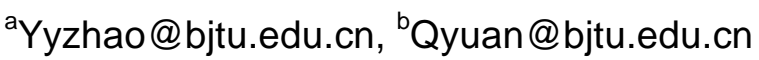

Keywords: assemble-type composited wall, pseudo-static tests, experimental

Abstract. For assemble-type composited wall, 4 pieces of wall which are 1/2 scale models were made. By pseudo-static tests under low cyclic loading, the aseismic behavior indexes were compared and analyzed, including failure characteristics, bearing capacity, stiffness, deformation, ductility, energy dissipation and so on. The results showed that: the frame which composed by rib-beams, rib-column and invisible frame can restraint bricks bearing and crack developing; the structure failed beginning at brick, then rib-grim, ending at invisible frame, this course can be described that the structure had multi-defense lines to resistant earthquake, and every components were used efficiently. The framework curve changed gently from yield to failure, there was no mutation and no collapse, which means the wall had a good collapse resistant capacity.

\section{Introduction}

Energy problem is a focus in all of the world, construction may consume one third of the whole energy. During the constructing, labor intensity is huge, construction period is long, and construction effect is low. Along with aging society coming, the construction labor will decrease. In order to build a conservation-minded society, saving energy and decreasing consume became more and more emergency. The development tendency for construction industry will be modularization, standardization and industrialization which can save labor. Prefabrication and site splice will great improve the construction effect, reduce construction period and decrease labor intensity. So developing new structure and component which will suit for the future became urgent.

Industrialized residence system using assemble-type composited wall is a new system. Assemble-type composited wall is the main load-bearing component in the system, and the wall also can be used as a heat preservation surround wall. The wall is a composed structure which composed with steel frame and filled foam cement. Steel frame composed with rib-beams, rib-column and invisible frame. The ultimate bearing capacity and seismic performance are the most important thing affecting the wall can be industrialized or not. Because of the wall is a new composed structure, the character of assemble-type composited wall is different from the traditional one. So we did an experimental which using 4 pieces of wall which are $1 / 2$ scale models through pseudo-static tests under low cyclic loading. The aseismic behavior indexes were compared and analyzed, including failure characteristics, bearing capacity, stiffness, deformation, ductility, energy dissipation and so on.

\section{Specimens design}

We made 4 specimens, and studied the difference what would affect the ultimate bearing capacity and the aseismic behavior indexes. The specimens design showed in table 1 , and the size of specimens showed in table 2.

Table 1. Design of assemble-type composited wall

\begin{tabular}{ccc}
\hline NO. & load & key feature of the specimen \\
\hline ECW-1 & low cyclic loading & Rectangle RC frame, filled foam cement, \# shaped frame composited wall \\
ECW-2 & low cyclic loading & Rectangle RC frame, filled foam cement, $\neq$ shaped frame composited wall \\
ECW-3 & low cyclic loading & Rectangle RC frame, filled foam cement, + shaped frame composited wall \\
ECW-4 & low cyclic loading & Rectangle RC frame, filled foam cement, + shaped frame composited wall \\
\hline
\end{tabular}


Table 2. size of specimen and reinforcement

\begin{tabular}{|c|c|c|c|c|c|c|c|c|c|c|}
\hline \multirow{2}{*}{$\begin{array}{l}\text { Length height } \\
\text { thinkness } \\
\text { /m }\end{array}$} & \multicolumn{4}{|c|}{ The size of frame and rib $/ \mathrm{mm}$} & \multicolumn{3}{|c|}{ The reinforcement of frame } & \multicolumn{3}{|c|}{ The reinforcement of rob } \\
\hline & $\begin{array}{l}\text { Frame } \\
\text {-beam }\end{array}$ & $\begin{array}{c}\text { Frame-c } \\
\text { olumn }\end{array}$ & $\begin{array}{c}\text { Rib-be } \\
\text { am }\end{array}$ & $\begin{array}{l}\text { Rib-co } \\
\text { lumn }\end{array}$ & $\begin{array}{l}\text { Frame } \\
\text {-beam }\end{array}$ & $\begin{array}{c}\text { Frame-c } \\
\text { olumn }\end{array}$ & stirrup & $\begin{array}{c}\text { Rib-be } \\
\text { am }\end{array}$ & $\begin{array}{l}\text { Rib-co } \\
\text { lumn }\end{array}$ & stirrup \\
\hline $1.4 \times 1.44 \times 0.1$ & 100 & 100 & 50 & 50 & $4 ф 6$ & 4ф6 & ф4@100 & $4 \phi 4$ & $4 ф 4$ & ф2@100 \\
\hline
\end{tabular}

There were three steps for making a specimen, which was prefabricated foam cement, prefabricated wall and cast in site. Fig 1 showed how to make the assemble-type composited wall.
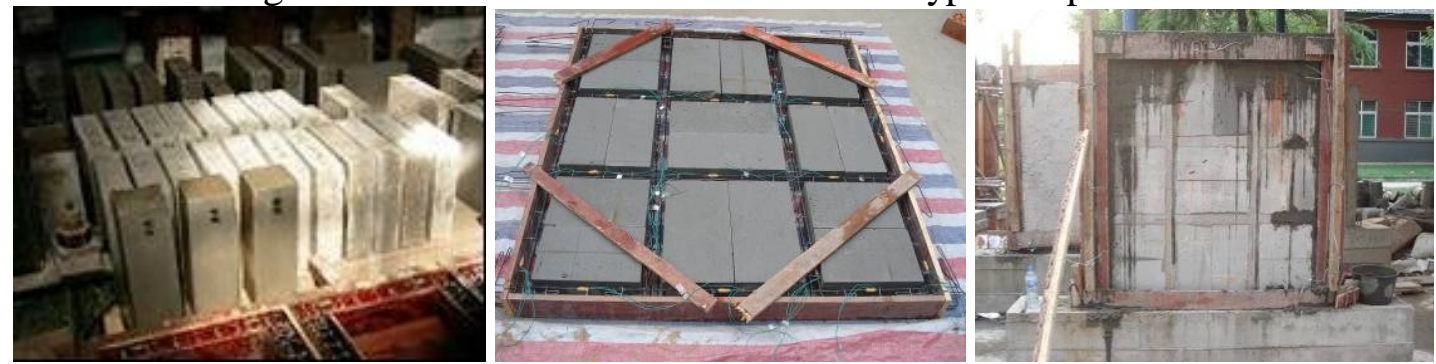

Fig 1. process of make assemble-type composited wall

\section{Load plan}

All the specimens were the same load plan.

1) Vertical load: the vertical press stress on the wall was the main effect which would influence the ultimate bearing capacity and the aseismic behavior indexes. According to the similarity relation, the vertical load of the specimen was $110 \mathrm{kN}$, one step, last 2 minutes. The vertical load press on the distributing beam through hydraulic jack, then distribute to hidden beam.

2) Horizon load: during the horizon load period, the vertical load dont change. Horizon load pressed on the top of the wall by reaction-force wall through hydraulic equipment. Horizon load was controlled by force in the first period and displacement in the second period. During the period controlled by displacement, cycled three times one step, until the bearing capacity dropped to $85 \%$ of the max value, then pulled the wall to destroy.

\section{Test procedure}

The fail procedure of ECW-1 specimen: fist put on vertical load which is $0.1 f_{c} A_{c}$ each step, about $54 \mathrm{kN}$. When the load is $0.5 f_{c} A_{c}$, the specimen began to make a slight sound, and this sound was continue when the load enlargement step by step until the load was $0.7 f_{c} A_{c}$. Then began to drop off the load with the step $0.1 f_{c} A_{c}$ until the load was $0.2 f_{c} A_{c}$, then kept the load constant. When the vertical load was stabilize, began to put on horizon load which was $10 \mathrm{kN}$ each step. There was nothing happened with the load was $10 \mathrm{kN}$, some vertical cracks appeared because of the failure of the mortar between the blocks with the load was $20 \mathrm{kN}$, the cracks began to develop with the load was $30 \mathrm{kN}$, some 45 degrees diagonal crack appeared in the blocks with the load was $40 \mathrm{kN}$, the cracks became longer with the load was $50 \mathrm{kN}$, some cement began to drop form the wall, some cracks extented to the rib-beam and lots of new cracks appeared with the load was $60 \mathrm{kN}$, lots of diagonal cracks appeared, some of them extented to the rib-column and some block began to drop from the wall with the load of $70 \mathrm{kN}$. The specimen began to make loudly sound and new diagonal crakes appeared, exist carks extented widely along the rib-beam or rib-column, horizon cracks appeared on the top of the right and on the bottom of the left of the frame-column, vertical cracks appeared between rib-column and frame-column, the bar in the frame-column began to yield and the horizon load reached limited with the load of $80-90 \mathrm{kN}$.

Then the test began to the period controlled by displacement which was the times of the point displacement under the ultimate load, cycleed three times one step. First using $12 \mathrm{~mm}$ cycled three times, both way 45 degrees diagonal crack appears quickly. Second using $24 \mathrm{~mm}$ cycled three times, the diagonal crack became wider, some block dropped off, the cracks in rib-beam and rib-column began to 
cut-through, some hole appeared in the middle because of the block dropping off. Third using $36 \mathrm{~mm}$ cycled three times, more blocks dropped off and rib-beam began to twist. Forth using 48mm cycled three times, horizon cracks cut-through on the top of the right of the frame-column. Fifth using $60 \mathrm{~mm}$ cycled three times, horizon cracks cut-through on the bottom of the left of the frame-column. Then stopped test, the specimen was not collapsed.

The fail procedure of ECW-2 specimen: fist put on vertical load which was $0.1 f_{c} A_{c}$ each step. When the load was $0.6 f_{c} A_{c}$, the specimen began to make a slight sound, some small horizon cracks appeared. When the load is $0.8 f_{c} A_{c}$, some cement on the surface began to drop off. Then unload to $0.2 f_{c} A_{c}$ whit the step $0.1 f_{c} A_{c}$. Then the vertical load was fixed, the horizon load began to load with the step of $10 \mathrm{kN}$. Before the load was $30 \mathrm{kN}$, they was normal. Some small grain dropped from the block and some small diagonal cracks appeared in the frame with the horizon load was $40 \mathrm{kN}$. The specimen began to make a sound, new diagonal cracks appeared and the existing cracks became wider with the horizon load was $50 \mathrm{kN}$. New diagonal cracks continue appeared, the existing cracks developed more widely, the most widely cracks was $0.2 \mathrm{~mm}$, some of them reached the rib-beam, some block separate from the rib-beam with the load was $60 \mathrm{kN}$. The specimen made a sound again, some block dropped off, the crack between rib-beam and rib-column was $0.1 \mathrm{~mm}$, and some horizon cracks appeared on the bottom of the right side with the load was $70 \mathrm{kN}$. Existing carks extented widely along the rib-beam or rib-column, the most widely cracks between rib-beam and rib-column was $0.2 \mathrm{~mm}$, some hole appeared in the middle because of the block dropping off, the horizon load reached limited with the load of $76 \mathrm{kN}$.

Then the test began to the period controlled by displacement which was the times of the point displacement under the ultimate load, cycled three times one step. First using $15 \mathrm{~mm}$ cycled three times, specimen began to sound loudly. Both way 45 degrees diagonal crack appeared quickly. Second using $30 \mathrm{~mm}$ cycled three times, the diagonal crack became wider, some block dropped off. Third using $45 \mathrm{~mm}$ cycled three times, the concrete in the top of the rib-column began to drop, and some bar appeared. Third using $60 \mathrm{~mm}$ cycled three times, the entire concrete on the top of the right side sticked out, some hole appeared in the middle because of the block dropping off, rib-beam twisted by the cycle load, and some cracks appeared between the rib-beam and rib-column. At this time, the load was a half of the ultimate load, and the test stopped.

The fail procedure of ECW-3 specimen: fist put on vertical load which was $0.1 f_{c} A_{c}$ each step. When the load wss $0.5 f_{c} A_{c}$, the specimen began to make a slight sound, some small cracks appeared. Along with the increasing load, some cracks extended, the final load was $0.7 f_{c} A_{c}$. Then unloaded to $0.2 f_{c} A_{c}$ whit the step $0.1 f_{c} A_{c}$. Then the vertical load was fixed, the horizon load began to load with the step of $5 \mathrm{kN}$. Some small diagonal cracks appeared, the specimen began to make a slight sound with the horizon load was $35 \mathrm{kN}$. Some cracks in the block located in the top of left side extented to the point which was the intersection of the rib-beam and rib-column, the biggest cracks width was $0.5 \mathrm{~mm}$ with the horizon load was $40 \mathrm{kN}$. The exiting diagonal cracks extended, long diagonal cracks appeared in both middle frame with the horizon load was $45 \mathrm{kN}$. The most widely cracks was $1.85 \mathrm{~mm}$ diagonal lots of cracks continue appeared, some horizon cracks appeared on the bottom of the left side with the horizon load was $55 \mathrm{kN}$. Some new diagonal cracks appeared in each frame, the existing cracks reached the rib-beam, two horizon cracks appeared in the right frame-column, the cracks in the left side of the bottom frame-column extended, and some block dropped, the left rib-beam separated from the frame-beam with the load was $60 \mathrm{kN}$. Lots of blocks dropped, the most widely cracks was $5 \mathrm{~mm}$, existing cracks extented widely along the rib-beam, cut-through cracks appeared on the bottom of the left frame-column, several horizon cracks appeared on the top of the right frame-column, the horizon load reached limited with the load of $69 \mathrm{kN}$.

Then the test began to the period controlled by displacement which was the times of the point displacement under the ultimate load, cycled three times one step. First using $20 \mathrm{~mm}$ cycled three times, both way 45 degrees diagonal crack appeared quickly, formed cross cracks. Second using 40mm 
cycled three times, the specimen made a continues sound, some hole appeared in the middle because of the block dropping off, the rib-beam cracks became wider. Third using $60 \mathrm{~mm}$ cycled three times, some bigger hole appeared in the middle because of the block dropping off, rib-beam heavily twisted under the cycle load, lots of concrete in the side of the rib-beam dropped. At this time, the load was a half of the ultimate load, and the test stopped.

The fail procedure of ECW-4 specimen: fist put on vertical load which is $0.1 f_{c} A_{c}$ each step. When the load was $0.5 f_{c} A_{c}$, the specimen began to make a slight sound, some small cracks appeared. Along with the increasing load, some cracks extended, the final load was $0.7 f_{c} A_{c}$. Then unload to $0.2 f_{c} A_{c}$ with the step $0.1 f_{c} A_{c}$. Then the vertical load was fixed, the horizon load began to load with the step of $5 \mathrm{kN}$. Some small diagonal cracks appeared with the horizon load was $10 \mathrm{kN}$. Some diagonal cracks appeared on the top of the right fame with the horizon load was $15 \mathrm{kN}$. Nearly all pieces appeared cracks with the horizon load was $20 \mathrm{kN}$. Small diagonal cracks appeared both end of the pieces with the horizon load was $25 \mathrm{kN}$. The exiting cracks extended, some of them extended to the rib-beam or rib-column, the widest cracks was $0.2 \mathrm{~mm}$, some small blocks began to drop off with the horizon load was $30 \mathrm{kN}$. New cracks appeared in the middle of the rib-beam, the exiting cracks continue extended, some small block dropped with the horizon load was $35 \mathrm{kN}$. Some long diagonal cracks appeared, horizon cracks appeared on the bottom of the left frame-column with the horizon load was $40 \mathrm{kN}$. Cut-through cracks appeared on the bottom of the left frame-column, all cracks on the block in frame uniformed distribution, the cracks near middle rib-beam distributed thickly, a diagonal crack extend from block through rib-column to frame-column, and some block dropped, the horizon load reached limited with the load of $55 \mathrm{kN}$.

Then the test began to the period controlled by displacement which was the times of the point displacement under the ultimate load, cycled three times one step. First using $20 \mathrm{~mm}$ cycled three times, the specimen began to make sound, more blocks dropped, a big concrete dropped from middle rib-beam, bar appeared and twisted, and cross cracks appeared in the block. Second using 40mm cycled three times, some big block dropped, diagonal cracks became wider, cut-through cracks appeared in the rib-beam and rib-column. Third using $60 \mathrm{~mm}$ cycled three times, rib-beam twisted even more, more blocks dropped, the block in upper frame separated from rib-beam, many cracks appeared near the both side of the frame-column. At this time, the test stopped.

\section{Test result}

\section{Hysteretic curve}

Hysteretic curve was the gist for restoring force model and nonlinear seismic response analysis, and the curve can reflect the deformation behavior under the cycle load, rigidity degeneration and energy consumption. The hysteretic curve showed as fig. 2 .

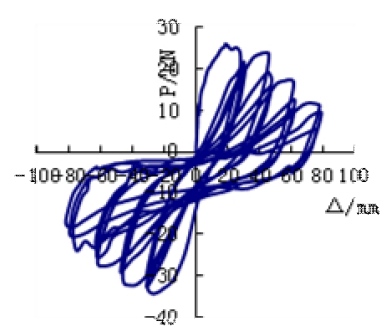

(a) $\mathrm{ECW}-1$

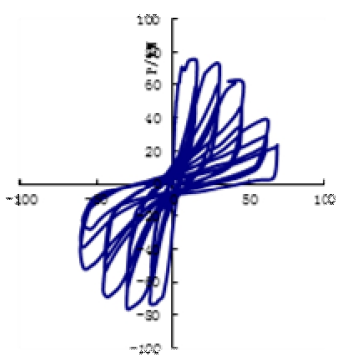

(b) $\mathrm{ECW}-2$

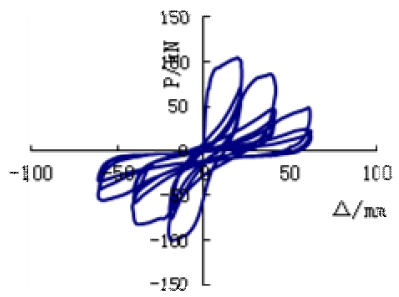

(c) $\mathrm{ECW}-3$

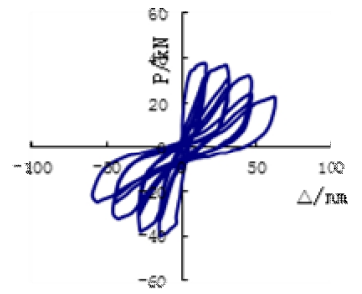

(d) ECW-4

Fig. 2 hysteretic curve of the wall

We can get the flowing conclusion by analyzing fig. 2 and the destruction process of the specimen.

1) slip phenomenon of the wall became highlight, that was indicate the most deformation of the wall was shear deformation and failure mode was shear failure. 
2) The hysteretic curve appeared the same character. Before the cracking period, the hysteretic curve was mostly straight, the rigidity degeneration and residual deformation wasn't obvious. Before yielded, the hysteretic curve was long and narrow, and the encircling area was small, the integral rigidity changed little, energy dissipation was little. After yielded, the hysteretic developed to bow style, the residual deformation was obvious, and the energy dissipation was bigger. Under the same step of the displacement control, the later cycle load was lower than the former one, the later cycle hysteretic curve encircling area was obvious smaller than the former one, that was indicated the wall had a strength rigidity degeneration, energy degeneration and dissipation degeneration. With the increasing number of the cycle load, the energy dissipation capacity was increasing, that indicated the contracture accumulated damage. Under the ultimate load, the hysteretic curve showed an obvious reversed S style and presented a strong pinched curve.

3) All the hysteretic curves from different wall displayed the similar pinched curve, the reason was that under the load, there was a slip phenomenon caused by adhesive failure between block and frame. But the ECW-3 specimen had a better integrality in block and frame.

4) the style of the hysteretic curves were mostly similar, and ECW-1 had a satiation one, that was indicated rib-beam and rib-column would help the composited wall increasing the anti-seismic property, but can't change the harmful property.

\section{Skeleton curve}

The contrast on the skeleton curve was shown fig.3.

The principle certainty of the feature points on each skeleton curve: the craze point, yield point, maximum load point and ultimate displacement point can respond the main feather of the skeleton curve.

Table 3 and fig. 3 showed that:

1) The specimen went through elastic, elastic-plastic and failure stage. From yield to failure, the skeleton curve varied gently and no jumping that showed the

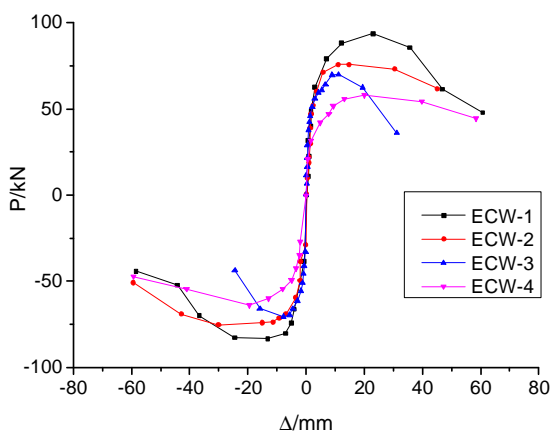

Fig.3 skeleton curve assemble-type composited wall bearing capacity declined gently, every component materials can play a part in bearing capacity and the wall had a good ductility.

Table 3 list of the test result

\begin{tabular}{|c|c|c|c|c|c|c|c|c|}
\hline \multirow{2}{*}{$\begin{array}{l}\text { specimens } \\
\text { No. }\end{array}$} & \multicolumn{2}{|c|}{ ECW-1 } & \multicolumn{2}{|c|}{ ECW-2 } & \multicolumn{2}{|c|}{ ECW-3 } & \multicolumn{2}{|c|}{ ECW-4 } \\
\hline & $\mathrm{P}$ & $\theta$ & $\mathrm{P}$ & $\theta$ & $P$ & $\theta$ & $\mathrm{P}$ & $\theta$ \\
\hline $\begin{array}{c}\text { block } \\
\text { cracking }\end{array}$ & 30 & 1470 & 50 & 541 & 20 & 3610 & 20 & 1806 \\
\hline $\begin{array}{l}\text { Rib-beam } \\
\text { cracking }\end{array}$ & 50 & 788 & 60 & 384 & 35 & 970 & 30 & 823 \\
\hline $\begin{array}{l}\text { Rib-beam } \\
\text { cut-through cracking }\end{array}$ & 60 & 383 & 70 & 223 & 60 & 152 & 40 & 313 \\
\hline $\begin{array}{l}\text { Rib-column } \\
\text { cracking }\end{array}$ & 70 & 271 & 60 & 384 & 45 & 516 & 45 & 185 \\
\hline $\begin{array}{l}\text { Rib-column } \\
\text { cut-through cracking }\end{array}$ & 88 & 111 & 70 & 223 & 55 & 254 & 55 & 105 \\
\hline $\begin{array}{l}\text { Frame-column } \\
\text { cracking }\end{array}$ & 88 & 111 & 70 & 223 & 55 & 254 & 40 & 313 \\
\hline $\begin{array}{l}\text { Frame-column } \\
\text { cut-through cracking }\end{array}$ & 93 & 56 & 76 & 89 & 70 & 66 & 55 & 105 \\
\hline Ultimate load & 93 & 56 & 76 & 89 & 70 & 66 & 58 & 66 \\
\hline $\begin{array}{l}\text { The maximum } \\
\text { displacement point }\end{array}$ & 47 & 21 & 39 & 21 & 36 & 21 & 28 & 16 \\
\hline
\end{tabular}

2) The skeleton curve forward and reverse presented an anti-symmetric style. The tension capacity and press capacity was basically the same that showed under the reverse load, the filling material crack closured in the composed wall, the wall can bearing load and can continually play a role. 


\section{Ductility factor}

Ductility factor showed the deformability when the structure entrance plastic period, which also said energy-dissipating capacity. For the ductility structure, intensity wasn't the only factor decided the aseismic capacity, but also the deformability. The list ductility factors were showed in table 4 .

Expression for ductility factor:

$$
\mu=\frac{\Delta_{u}}{\Delta_{y}}
$$

Note: $\Delta_{u}:$ Ultimate displacement, $\Delta_{y}:$ Yield displacement

Table 4 ductility factor of the wall

\begin{tabular}{ccccc}
\hline No. & ECW-1 & ECW-2 & ECW-3 & ECW-4 \\
\hline Ductility factor & 4.9 & 4.5 & 4.5 & 4.9 \\
\hline
\end{tabular}

The table 4 showed that the ductility factor of the composed wall was 4.5 to 5.5 , indicated the wall had a good deformability after yielding.

\section{Conclusion}

The ECW-1, ECW-2, ECW-3 and ECW-4 specimens failed by share capacity. The frame which composed by rib-beams, rib-column and invisible frame can restraint bricks bearing and crack developing; the structure failed beginning at brick, then rib-grim, ending at invisible frame, this course can be described that the structure had multi-defense lines to resistant earthquake, and every components were used efficiently. It was reasonable. The framework curve changed gently from yield to failure, there was no mutation and no collapse. The skeleton curve had a long extend period, the feather load was obvious, and the rigidity degenerate gently. The wall wasn't collapsed when it failed, which meaned the wall had a good collapse resistant capacity.

\section{References}

[1] Forward-looking industry research institute: Intelligent building industry market prospect and investment strategic planning analysis report in China during the year 2013-1017 (2013)

[2] Xi'an University of Architecture and Technology: science and technology report: theory and application research on multi-ribbed wall slab light-weight frame structure (2000)

[3] Wei Huang. Anti-seismic resistant behavior and design theoretical research on multi-ribbed composite wall. Xi' an University of Architecture and Technology(2004)

[4] Dong Zhao, Ping Chen and Qianfeng Yao: Limited element analyses on the multi-rib wall-pannel light-weighted frame structure. J. Xi'an Univ. of Arch. \& Tech(2002) Vol.34 No.1 p1-4,13 